\title{
Keanekaragaman dan Dominasi Gulma pada Pertanaman Jagung di Lahan Kering Kecamatan Marisa Kabupaten Pohuwato
}

\author{
(Diversity and Domination of Weeds in Corn Planting in Dry Land in Marisa District, Pohuwato District) \\ Erse Drawana Pertiwi ${ }^{1}$, dan Muh. Arsyad ${ }^{1}$ \\ ${ }^{1}$ Fakultas Pertanian, Universitas Ichsan Gorontalo \\ *Email korespondensi: ersedp@gmail.com; maner_b1@yahoo.com \\ Diterima 18 Agustus 2018/Disetujui 05 Februari 2019
}

\begin{abstract}
Weed is one of the plant-disturbing organisms (OPT) or plant pest bodies. Weeds can grow around plants, including corn plants. This study aims: 1) To find out the weeds that dominate the corn crop in Marisa Subdistrict, Pohuwato Regency, 2) To find out the weed diversity index that grows in the corn crop area. The research method used is a survey and purposive sampling method (determination of research locations and samples intentionally) based on the level of adoption of farmers in weed control in corn crops. The results showed that the highest SDR value in maize plantations aged 45 HST was found on Kusa-Kusa Grass (Echinochloa colonum) which was 33\%. Whereas the highest SDR value in corn crop aged 55 HST is found in Teki (Cyperus rotundus) which is $51 \%$. Diversity Index $\left(H^{\prime}\right)$ on 45 HST maize cropping area is 1.631 and corn planting area of 55 HST age is 1.763 which means $H^{\prime}$ is classified as medium $\left(1<H^{\prime}<3\right)$.
\end{abstract}

Keywords: diversity, dominance, weed

\begin{abstract}
ABSTRAK
Gulma adalah salah satu Organisme Pengganggu Tanaman (OPT) atau jasad pengganggu tanaman. Gulma dapat tumbuh disekitar tanaman, termasuk tanaman jagung. Penelitian ini bertujuan : 1) Untuk mengetahui gulma yang mendominasi pertanaman jagung di Kecamatan Marisa, Kabupaten Pohuwato, 2) Untuk mengetahui indeks keanekaragaman gulma yang tumbuh pada areal pertanaman jagung. Metode penelitian yang digunakan adalah survei dan metode purposive sampling (penentuan lokasi penelitian dan sampel secara sengaja) yang berdasarkan pada tingkat adopsi petani dalam pengendalian gulma di pertanaman jagung. Hasil penelitian menunjukkan bahwa nilai SDR tertinggi pada pertanaman jagung umur 45 HST terdapat pada Rumput Kusa-Kusa (Echinochloa colonum) yaitu 33\%. Sedangkan Nilai SDR tertinggi pada pertanaman jagung umur 55 HST terdapat pada Teki (Cyperus rotundus) yaitu 51\%. Indeks Keanekaragaman (H') pada lahan pertanaman jagung umur 45 HST yaitu 1.631 dan lahan pertanaman jagung umur 55 HST yaitu 1.763 yang berarti H' tergolong sedang $\left(1<H^{\prime}<3\right)$.
\end{abstract}

Kata kunci : dominansi, gulma, keanekaragaman

\section{PENDAHULUAN}

Jagung merupakan salah satu tanaman budidaya yang saat ini banyak diusahakan oleh masyarakat. Selain sebagai sumber karbohidrat, jagung juga ditanam sebagai pakan ternak, penghasil minyak (dari biji), diolah menjadi tepung (dari biji), dan bahan baku industri. Jagung yang telah mengalami rekayasa genetika saat ini juga ditanam sebagai bahan baku farmasi dan bahan ekspor non migas (Subandi dalam Muharrami, 2011). Salah satu masalah utama yang dihadapi dalam budidaya tanaman jagung yaitu pertumbuhan gulma yang berada disekitar tanaman.

Gulma adalah salah satu organisme pengganggu tanaman (OPT) atau jasad pengganggu tanaman. Keberadaan gulma disekitar pertanaman merupakan salah satu masalah penting dalam budidaya tanaman, khususnya dalam hal peningkatan produksi. Semakin lama gulma tumbuh bersama dengan tanaman pokok, semakin hebat persaingannya, pertumbuhan tanaman pokok semakin terlambat, dan hasilnya semakin menurun.

Pengenalan jenis-jenis gulma dominan merupakan langkah awal yang menentukan keberhasilan pengendalian gulma di areal pertanaman jagung. Banyak spesies gulma yang tumbuh di lahan kering pada pertanaman jagung, sehingga untuk mengenal dan menentukan cara pengendaliannya perlu diketahui sifat-sifat dan biologi gulma terutama cara berkembang biak. Disamping itu juga penggolongan yang mencirikan berbagai sifat karakteristiknya.

Assosiasi jenis gulma tertentu dengan tanaman pokok dan habitat, perannya terhadap tanaman budidaya serta penggolongan yang dikaitkan dengan responnya terhadap 
cara pengendalian adalah penting sebagai bahan pertimbangan bagi petugas lapang (Tjokrowardojo dan Djauhariya). Inventarisasi dan analisis vegetasi gulma yang dominan di areal budidaya tanaman jagung sangat membantu tindakan untuk pengendalian yang tepat.

Penelitian yang terkait dengan keanekaragaman dan dominansi gulma dilakukan pada lahan pertanaman jagung yang terdapat di Kabupaten Pasaman, Padang. Berdasarkan hasil penelitian Muharrami (2011) ditemukan 16 Famili, 35 genus dan 45 spesies gulma dengan jumlah total 12175 individu gulma pada pertanaman jagung di lahan kering dan 5,446 individu gulma pada pertanaman jagung di lahan sawah. Borreria alata mendominasi pertanaman jagung di lahan kering sebanyak 6,680 individu (SDR 40.03\%), sedangkan Cuphea carthagenensis mendominasi pertanaman jagung di lahan sawah sebanyak 1815 individu (SDR $19.74 \%$ ). Indeks keanekaragaman gulma di lahan kering 2.38 dan di lahan sawah 2.72, nilai indeks keanekaragaman tersebut tergolong sedang. Indeks kesamaan gulma dari kedua lahan pertanaman tersebut rendah dengan nilai sebesar 20\% (Muharrami 2011).

\section{METODOLOGI PENELITIAN}

\section{Lokasi Penelitian}

Lokasi dari penelitian ini adalah Kabupaten Pohuwato yang merupakan salah satu sentra produksi jagung di Propinsi Gorontalo. Kecamatan Marisa merupakan salah satu wilayah yang terdapat di Kabupaten Pohuwato, yang secara sengaja (purposive sampling) dipilih menjadi tempat penelitian ini.

\section{Bahan dan Alat}

Bahan yang digunakan dalam penelitian ini adalah kertas label, tali rafia, kantong plastik, kertas koran. Sedangkan alat yang digunakan adalah camera, patok, meteran, penggaris, kalkulator, cutter, parang, gunting dan alat tulis menulis.

\section{Metode Penelitian}

Metode yang digunakan dalam penelitian ini adalah metode kualitatif dan kuantitatif. Metode kualitatif yang digunakan dalam penelitian ini yaitu dengan mengidentifikasi gulma yang ditemukan pada pertanaman jagung serta menginterpretasikan pengendalian gulma yang dilakukan oleh petani pada lahan pertanaman jagung di lokasi penelitian. Sedangkan metode kuantitatif yang digunakan yaitu dengan menghitung dan menganalisis vegetasi gulma yang dominan serta keanekaragamannya pada pertanaman jagung.

\section{Teknik Pengumpulan Data}

Teknik pengumpulan data yang akan dilakukan dalam penelitian ini adalah sebagai berikut :
1. Observasi lapang, dilakukan untuk menentukan lokasi penelitian.

2. Pengambilan sampel gulma, dilakukan dengan membentuk plot-plot pengamatan secara diagonal.

3. Wawancara mendalam (indepth interview), dilakukan dalam pengambilan data primer untuk mendapatkan data kualitatif berupa opini maupun tanggapan dari informan.

4. Dokumentasi, dilakukan untuk mengumpulkan data-data visual yang terkait dengan spesies gulma, keadaan lahan pertanaman jagung di lokasi penelitian.

\section{Tahapan Penelitian}

Tahapan penelitian yaitu dengan menentukan lokasi penelitian secara purposive sampling (penentuan lokasi penelitian dan sampel secara sengaja) yang berdasarkan pada tingkat adopsi petani dalam pengendalian gulma di pertanaman jagung. Pengambilan sampel gulma dilakukan pada areal pertanaman jagung. Titik pengambilan sampel berjumlah 9 (sembilan) plot. Plot sampel tersebut diatur secara diagonal dan tiap plot dibatasi dengan menggunakan tali rafia. Gulma yang ditemukan dicatat jenisnya dan dihitung sesuai dengan lahan dan nomor petak contohnya. Setelah dilakukan identifikasi, lalu dilakukan tabulasi dan dianalisis data vegetasi gulma dengan variabel kerapatan mutlak, kerapatan nisbi, frekuensi mutlak, frekuensi relatif, nilai penting, Summed Dominance Ratio (SDR), dan indeks keanekaragaman (H') gulma.

\section{Analisis Data}

Data komposisi jenis penyusun vegetasi gulma dianalisis secara kuantitatif. Komposisi jenis penyusun vegetasi gulma dalam areal pertanaman jagung ditentukan dengan menghitung kerapatan mutlak, kerapatan nisbi, frekuensi mutlak, frekuensi nisbi, nilai penting dan Summed Dominance Ratio (SDR) atau Nisbah Jumlah Dominan. Untuk menghitung kerapatan dan frekuensi serta dominansi gulma, maka digunakan rumus menurut Sembodo (2010), yaitu :

Kerapatan Mutlak $(K M)=$

$\underline{\text { Jumlah satu jenis gulma }}$

Luas area

Kerapatan Nisbi $(K N)=$

$\frac{\text { Kerapatan mutlak satu jenis gulma }}{\text { Total kerapatan mutlak semua jenis gulma }} \times 100 \%$

Frekuensi $\operatorname{Mutlak}(F M)=$

Jumlah plot satu jenis

Jumlah semua plot

Frekuensi Nisbi $(F N)=$

$\frac{\text { Frekuensi mutlak satu jenis gulma }}{\text { Total frekuensi mutlak semua jenis gulma }} \times 100 \%$

Nilai Penting $(N P)=$ Kerapatan Nisbi + Frekuensi Nisbi 
Summed Dominance Ratio $(S D R)=$

Nilai Penting 2

Indeks Keanekaragaman Jenis $\left(H^{\prime}\right)=$ $-\sum_{i=1}^{S} p i \quad \ln p i$

Keterangan :

$\mathrm{H}^{\prime}$ = Indeks keanekaragaman jenis

$\mathrm{Pi}=$ Peluang kepentingan untuk tiap spesies $=n i / \mathrm{N}$

$\mathrm{ni}=$ Jumlah individu setiap satu spesies

$\mathrm{N}=$ Jumlah total individu

Menurut Magurran dalam Afrianti et al. (2014), klasifikasi nilai keanekaragaman sebagai berikut :

$\mathrm{H}^{\prime}<1=$ Keanekaragaman rendah

$1<\mathrm{H}^{\prime}<3=$ Keanekaragaman sedang

$\mathrm{H}^{\prime}>3=$ Keanekaragaman tinggi

\section{HASIL PENELITIAN}

\section{Dominansi Gulma}

Berdasarkan hasil penelitian, terdapat tujuh spesies gulma dari empat Famili. Gulma dominan pada pertanaman jagung fase vegetatif umur 45 HST terdapat pada rumput kusa-kusa (Echinochloa colonum) yang berasal dari Famili Poaceae dan gulma Teki (Cyperus rotundus) dari famili Cyperaceae. Hasil analisis vegetasi gulma disajikan pada Tabel 1.

Nilai kerapatan relatif gulma tertinggi terdapat pada spesies Teki (Cyperus rotundus) yaitu $48 \%$ sedangkan kerapatan relatif terendah terdapat pada spesies rumput belulang (Eleusine indica) dan Rumput Empiritan (Eragrotis tenella) yaitu $1 \%$. Gulma lainnya yang memiliki Kerapatan nisbi yang tinggi adalah rumput Kusa-Kusa (Echinochloa colonum) yaitu $40 \%$. Hal ini menunjukkan bahwa kedua spesies tersebut memiliki jumlah populasi tertinggi dan penyebaran yang luas dibanding gulma lain. Sedangkan pada analisis Frekuensi Nisbi (FN), rumput Kusa-Kusa (Echinochloa colonum) memiliki persentase kemunculan terbanyak yaitu 26\%. Rumput Kusa-Kusa paling sering ditemukan pada setiap plot yang diamati pada pertanaman jagung.

Nilai Penting tertinggi berada pada spesies E. colonum yaitu 0.661 . Sedangkan C. rotundus memiliki Nilai Penting tertinggi kedua (0.624) setelah Rumput Kusa-Kusa. Analisis untuk Nilai Penting (NP) suatu gulma diperoleh dari variabel Kerapatan Mutlak dan Frekuansi Mutlak. Menurut Pribadi dan Anggraeni (2010), Frekuensi merupakan banyaknya petak pengamatan dari spesies gulma tertentu yang berhasil ditemukan, sedangkan kerapatan adalah banyaknya jumlah gulma tertentu pada satu petak pengamatan dibagi luas petak pengamatan. Berdasarkan hal tersebut maka diperoleh Nilai Penting.

Gulma yang mendominasi lahan pertanaman jagung umur 45 HST adalah E. colonum dan C. rotundus. Hal ini dapat dilihat dari Nilai SDR (Summed Dominance Ratio) kedua gulma ini. Nilai SDR E. colonum yaitu 33\% dan C. rotundus adalah $31 \%$. Hal ini menunjukkan bahwa kedua gulma tersebut mendominasi lahan pertanaman jagung karena mempunyai daya adaptasi yang tinggi dengan tanaman yang beragam. Menurut Kastanja (2015), E. colona ini merupakan gulma yang hampir selalu berasosiasi dengan tanaman jagung. Jenis gulma ini termasuk dalam jenis gulma setahun yang mampu menghasilkan biji dalam jumlah yang banyak dan memiliki masa dormansi biji yang panjang sehingga dapat lebih bertahan hidupnya.

Selain daya saing yang tinggi, gulma Rumput KusaKusa memiliki biji yang mampu bertahan sampai tiga tahun di lahan. Biji-biji tersebut masih mampu berkecambah setelah enam periode musim tanam.

Gulma teki memiliki nilai SDR yang tinggi setelah Rumput Kusa-Kusa pada pertanaman jagung di fase vegetatif tanaman. Teki merupakan salah satu jenis gulma yang banyak ditemukan pada lokasi penelitian karena memiliki pola penyebaran yang luas pada lahan pertanaman jagung. Distribusi yang luas dipengaruhi oleh kemampuan Teki dalam berkembang biak. Organ perbanyakan Teki dapat berasal dari biji ataupun umbi. Antarumbi yang berasal dari satu individu dihubungkan dengan sulur-sulur. Sembodo (2010) menyatakan bahwa pada tanah yang gembur dan subur, perkembangan umbi Teki sangat cepat.

Tabel 1. Kerapatan Nisbi, Frekuensi Nisbi, Nilai Penting, dan Summed Dominance Ratio Gulma pada Pertanaman Jagung Umur 45 HST

\begin{tabular}{lllcccc}
\hline Famili & Spesies & Nama Indonesia & $\begin{array}{c}\text { KN } \\
(\%)\end{array}$ & $\begin{array}{c}\text { FN } \\
(\boldsymbol{\%})\end{array}$ & NP & $\begin{array}{c}\text { SDR } \\
(\%)\end{array}$ \\
\hline Euphorbiaceae & Euphorbia hirta & Patikan & 5 & 23 & 0.278 & 14 \\
Portulacaceae & Portulaca oleraceae & Krokot & 2 & 14 & 0.160 & 8 \\
Cyperaceae & Cyperus rotundus & Teki & 48 & 14 & 0.624 & 31 \\
Poaceae & Echinochloa colonum & Rumput Kusa-Kusa & 40 & 26 & 0.661 & 33 \\
Poaceae & Eleusine indica & Belulang & 1 & 9 & 0.100 & 5 \\
Poaceae & Eragrostis tenella & Empiritan & 1 & 9 & 0.098 & 5 \\
Poaceae & Cynodon dactilon & Kawatan & 2 & 6 & 0.080 & 4 \\
\hline
\end{tabular}

Sumber : Data Primer Setelah Diolah 
Tabel 2. Kerapatan Nisbi, Frekuensi Nisbi, Nilai Penting, dan Summed Dominance Ratio (SDR) Gulma pada Pertanaman Jagung Umur 55 HST

\begin{tabular}{lllcccc}
\hline \multicolumn{1}{c}{ Famili } & \multicolumn{1}{c}{ Spesies } & \multicolumn{1}{c}{ Nama Indonesia } & $\begin{array}{r}\text { KN } \\
(\boldsymbol{\%})\end{array}$ & $\begin{array}{c}\text { FN } \\
(\boldsymbol{\%})\end{array}$ & NP & $\begin{array}{c}\text { SDR } \\
(\boldsymbol{\%})\end{array}$ \\
\hline Euphorbiaceae & Euphorbia hirta & Patikan & 1 & 6 & 0.073 & 4 \\
Portulacaceae & Portulaca oleraceae & Krokot & 0 & 3 & 0.032 & 2 \\
Cyperaceae & Cyperus rotundus & Teki & 83 & 19 & 1.017 & 51 \\
Euphorbiaceae & Phyllanthus niruri & Meniran & 0 & 6 & 0.066 & 3 \\
Asteraceae & Sonchus arvensis & Tempuyung & 0 & 3 & 0.032 & 2 \\
Leguminoceae & Mimosa pudica & Puteri Malu & 10 & 19 & 0.289 & 15 \\
Oxalidaceae & Oxalis barrelieri & Calincing & 2 & 6 & 0.084 & 4 \\
Convolvulaceae & Ipomoea triloba & Kumkari & 0 & 3 & 0.035 & 2 \\
Poaceae & Echinochloa colona & Tuton. Rumput Kusa-Kusa & 0 & 3 & 0.032 & 2 \\
Poaceae & Eleusine indica & Belulang & 0 & 3 & 0.032 & 2 \\
Poaceae & Eragrostis tenella & Empiritan & 1 & 13 & 0.135 & 7 \\
Poaceae & Cynodon dactilon & Grintingan, Kawatan & 1 & 13 & 0.138 & 7 \\
Poaceae & Axonopus compressus & Rumput Pait & 0 & 3 & 0.032 & 2 \\
\hline
\end{tabular}

Sumber : Data Primer Setelah Diolah

Apabila sulur penghubung terputus, maka umbi yang terpisah akan menjadi individu baru. Pernyataan ini didukung pula oleh Suryaningsih (2011) bahwa umbi Teki terbentuk setelah tiga minggu dari pertumbuhan awal, selanjutnya membentuk rimpang dan umbi. Hal tersebut sesuai dengan sifat dari Famili Cyperaceae yang dapat tumbuh dalam kondisi yang ekstrim karena termasuk gulma ganas. Akibatnya gulma tersebut dapat menguasai ruang tempat tumbuh dan unggul dalam bersaing dengan tanaman pokok.

Berdasarkan hasil pengamatan dan identifikasi gulma dilapangan diperoleh bahwa pada pertanaman jagung umur 55 HST di Kecamatan Marisa terdapat 14 spesies gulma dari sembilan famili. Hasil analisis vegetasi gulma pada pertanaman jagung umur 55 HST disajikan pada Tabel 2.

Nilai kerapatan terbesar terdapat pada jenis gulma Teki (Cyperus rotundus) yaitu 83\% sedangkan pada variabel pengamatan untuk nilai Frekuensi Nisbi (FN) diperoleh bahwa Teki dan Puteri Malu merupakan gulma yang paling sering muncul disetiap plot pengamatan pertanaman jagung umur 55 HST. Nilai FN C. rotundus dan M. pudica masingmasing yaitu $19 \%$. Hal ini berpengaruh pada nilai penting pada kedua gulma tersebut, semakin tinggi nilai kerapatan nisbi dan frekuensi nisbi suatu gulma pada areal pertanaman maka semakin tinggi pula nilai penting gulma tersebut. Berdasarkan hal tersebut, maka diperoleh Nilai Penting tertinggi yang berada pada Famili Cyperaceae yaitu gulma Teki (Cyperus rotundus) dengan NP 1.017.

Nilai SDR tertinggi pada pertanaman jagung umur 55
HST terdapat pada spesies Teki (Cyperus rotundus L.) dengan nilai $51 \%$. Hal ini berarti Teki mendominasi ruang tumbuh pada pertanaman jagung dibanding dengan gulma lainnya yang tumbuh di sekitar lokasi penelitian. Teki memiliki daya adaptasi luas untuk tumbuh dan berkembang pada lingkungan yang memiliki faktor pembatas. Hal ini sesuai dengan Kastanja (2011) yang menyatakan bahwa jenis gulma tekian memiliki daya tahan luar biasa terhadap pengendalian mekanik karena umbi batang di dalam tanah yang mampu bertahan selama berbulan-bulan.

\section{Indeks Keanekaragaman Gulma}

Indeks keanekaragaman dari vegetasi gulma yang terdapat dipertanaman jagung umur 45 dan 55 Hari Setelah Tanam di Kecamatan Marisa disajikan pada Tabel 3.

Berdasarkan hasil analisis indeks keanekaragaman, diperoleh bahwa tiap spesies gulma ataupun total indeks keanekaragaman semua spesies yang terdapat pada pertanaman jagung umur 45 dan 55 HST tergolong sedang yang ditunjukkan dari indeks keanekaragaman yang berkisar 1.631-1.763. Menurut Magurran dalam Afrianti et al. (2014), indeks keanekaragaman dikatakan sedang bila nilai tersebut berkisar $1<\mathrm{H}^{\prime}<3$. Lebih lanjut Afrianti (2014) menyatakan bahwa suatu komunitas dikatakan memiliki keanekaragaman jenis yang tinggi jika komunitas itu disusun oleh banyak jenis. Sebaliknya suatu komunitas dikatakan memiliki keanekaragaman jenis yang rendah apabila komunitas tersebut disusun oleh jenis yang sedikit. 
Tabel 3. Indeks Keanekaragaman Gulma pada Pertanaman Jagung umur 45 dan 55 HST di Kecamatan Marisa, Kabupaten Pohuwato

\begin{tabular}{|c|c|}
\hline \multicolumn{2}{|c|}{ Jagung Umur 45 Hari Setelah Tanam } \\
\hline Spesies & $\mathbf{H}^{\prime}$ \\
\hline Echinochloa colona & 0.274 \\
\hline Euphorbia hirta & 0.202 \\
\hline Portulaca oleraceae & 0.363 \\
\hline Cyperus rotundus & 0.366 \\
\hline Eleusine indica & 0.149 \\
\hline Eragrostis tenella & 0.148 \\
\hline Cynodon dactilon & 0.129 \\
\hline Total & 1.631 \\
\hline \multicolumn{2}{|c|}{ Jagung Umur 55 Hari Setelah Tanam } \\
\hline Spesies & $\mathbf{H}^{\prime}$ \\
\hline Euphorbia hirta & 0.121 \\
\hline Portulaca oleraceae & 0.067 \\
\hline Cyperus rotundus & 0.344 \\
\hline Phyllanthus niruri & 0.113 \\
\hline Sonchus arvensis & 0.067 \\
\hline Mimosa pudica & 0.279 \\
\hline Oxalis barrelieri & 0.134 \\
\hline Ipomoea triloba & 0.071 \\
\hline Echinochloa colona & 0.067 \\
\hline Eleusine indica & 0.067 \\
\hline Eragrostis tenella & 0.182 \\
\hline Cynodon dactilon & 0.185 \\
\hline Axonopus compressus & 0.067 \\
\hline Total & 1.763 \\
\hline
\end{tabular}

Sumber : Data Primer Setelah Diolah

\section{KESIMPULAN}

Berdasarkan hasil penelitian tentang keanekaragaman dan dominansi gulma pada lahan pertanaman jagung, maka dapat disimpulkan

1. Gulma dominan pada pertanaman jagung fase vegetatif umur 45 HST terdapat pada Rumput Kusa-Kusa (Echinochloa colonum) dengan nilai SDR 33\%, sedangkan Nilai SDR tertinggi pada pertanaman jagung fase generartif umur 55 HST terdapat pada Teki (Cyperus rotundus) yaitu $51 \%$

2. Indeks Keanekaragaman (H') gulma pada lahan pertanaman jagung umur 45 HST yaitu 1.631 dan lahan pertanaman jagung umur 55 HST yaitu 1.763 yang berarti H' tergolong sedang $\left(1<\mathrm{H}^{\prime}<3\right)$.

\section{SARAN}

Saran dari penelitian ini yaitu Keanekaragaman dan dominansi gulma sebaiknya perlu diketahui di areal pertanaman jagung agar dapat dijadikan bahan pertimbangan dalam pengendalian gulma yang tepat dan efektif.

\section{DAFTAR PUSTAKA}

Afrianti I, Yolanda R, Purnama A.A. 2014. Analisis Vegetasi Gulma pada Perkebunan Kelapa Sawit (Elaeis quinensis Jacq.) di Desa Suka Maju Kecamatan Rambah Kabupaten Rokan Hulu. Universitas Pasir Pengaraian.

Global Species. 2013a. Cynodon dactylon. http://www.globalspecies.org/ntaxa/863517 Diakses tanggal 3 Juli 2018.

2013b. Ipomoea triloba (littlebell; three-lobed morningglory).http://www.globalspecies.org/ntaxa/91 1860 Diakses tanggal 3 Juli 2018

.2013c. Echinochloa colona (littlebell; three-lobed morning glory). http://www.globalspecies.org/ntaxa/862662 Diakses tanggal 3 Juli 2018

Kastanja A.Y. 2011. Identifikasi Jenis dan Dominansi Gulma pada Pertanaman Padi Gogo (Studi Kasus di Kecamatan Tobelo Barat, Kabupaten Halmahera 
Utara). Jurnal Agroforestri Volume VI Nomor 1 Maret 2011.

Muharrami R. 2011. Analisis Vegetasi Gulma pada Pertanaman Jagung (Zea mays L.) di Lahan Kering dan Lahan Sawah di Malampah Kabupaten Pasaman. Universitas Andalas. Padang.

Plantamor. 2012a. Rumput Belulang Eleusine indica (L.) Gaertn.http://www.plantamor.com/index.php?plant=1 $\underline{698}$. Diakses tanggal 7 Juli 2018.

2012b. Grintingan Cynodon dactylon(L.) Pers. http://www.plantamor.com/index.php?plant=438. Diakses tanggal 7 Juli 2018.

Plantamor. 2012a. Bayam Duri (Amaranthus spinosus L.) http://www.plantamor.com/index.php?plant=85. Diakses tanggal 10 Juli 2018. 2012b. Gelang (Portulaca oleraceae). Tersedia pada:

http://www.plantamor.com/index.php?plant=1049

Diakses tanggal 10 Juli 2018.

Pribadi, A., I. Anggraeni. 2011. Jenis dan Struktur Gulma pada Tegakan di Lahan Gambut (Studi Kasus pada HPHTI PT Harara Abadi, Riau). Jurnal Tekno Hutan Tanaman. 4(1):33-40.

Sembodo, D.R.J. 2010. Gulma dan Pengelolaannya. Graha Ilmu. Yogyakarta.

Suryaningsih, M. Joni, A.A.K. Darmadi. 2011. Inventarisasi Gulma pada Tanaman Jagung (Zea mays L.) di Lahan Sawah Kelurahan Padang Galak, Denpasar Timur, Kodya Denpasar, Provinsi Bali. Jurnal Simbiosis. 1(1):1-8. 